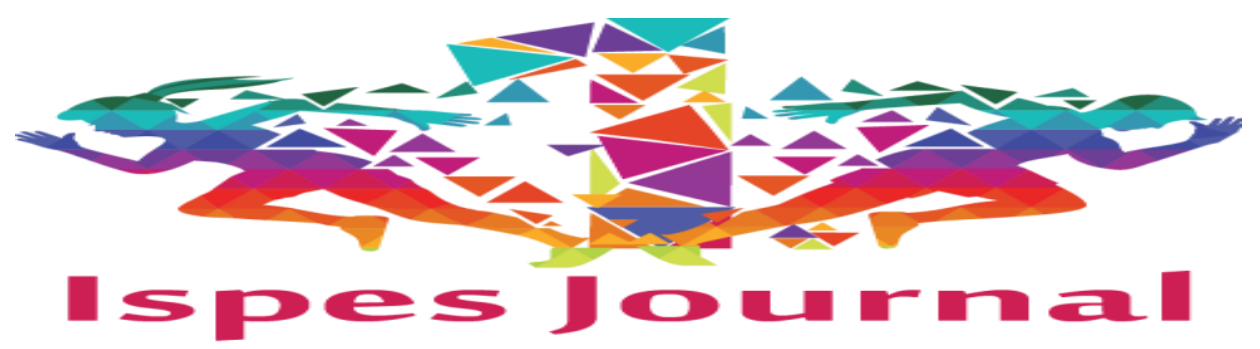

ULUSLARARASI BEDEN EĞİTIMİ SPOR REKREASYON VE DANS Dergisi Y11:1, Sayı:1, Aralık 2018, s.47-62

\author{
Arş. Gör. Murat YILMAZ ${ }^{1}$, Prof. Dr. Hasan AKKUŞ² \\ 1. Adıyaman Üniversitesi Beden Eğitimi Ve Spor Yüksekokulu, mrtyilmaz@adiyaman.edu.tr. \\ 2. Selçuk Üniversitesi Spor Bilimleri Fakültesi, hakkus@selcuk.edu.tr
}

\title{
8 Haftalık Kuvvet Antrenmanının 13-16 Yaş Arası Çocuklarda Bazı Fiziksel Uygunluk Parametrelerine Etkisinin İncelenmesi ÖZET
}

$\mathrm{Bu}$ araştırmanın amacı 8 haftalık kuvvet antrenmanının 13-16 yaş arası çocukların bazı fiziksel uygunluk parametreleri üzerine etkisini incelemektir.

Araştırmaya yaşları 13-16 arasında değişen, 12 erkek ve 10 kadın öğrenci toplam 22 çocuk katılmıştır. Test ve ölçümlere sağlık açısından spor yapmasında sakınca olmayan ve çalışmaya gönüllü olarak katılan çocuklar alınmıştır. Araştırmaya katılan öğrencilerin yaş, boy uzunluğu ve vücut ağırlığı ortalamaları kızlar için sirasıyla $14,50 \pm 1,26$ y11, $1,52 \pm 0,05 \mathrm{~m}$ ve $51,00 \pm 8,00 \mathrm{~kg}$ olarak erkekler için ise $14,50 \pm 0,90 \mathrm{y} 1 \mathrm{l}, 1,62 \pm 0,09 \mathrm{~m}$ ve $53,58 \pm 7,10 \mathrm{~kg}$ olarak tespit edilmiştir. Bazı fiziksel uygunluk parametrelerinin belirlenmesi için 8 haftalık kuvvet antrenmanı uygulanmıştır. Bazı fiziksel uygunluk parametrelerinin belirlenmesi için flamingo denge testi, otur ve eriş testi, durarak çift ayak öne sıçrama, dikey sıçrama ve anaerobik güç, kavrama kuvveti testi, mekik testi, bükülü kol tutunma testi,10mx5 mekik koşusu testleri uygulanmıştır. Vücut kompozisyonu ise vücut ağırlığının (kg), boy uzunluğunun (m) karesine bölünmesiyle hesaplanmıştır.

Çalışmada uygulanan tüm testlerin yaş gruplarına ve cinsiyete göre yüzdelik dağılımları hesaplanarak değerlendirilmiştir. Kadınlar için; flamingo denge testi, otur ve eriş testi, durarak çift ayak öne sıçrama, dikey sıçrama ve anaerobik güç, kavrama kuvveti testi, mekik testi, bükülü kol tutunma testi,10mx5 mekik koşusu testleri ön-test ve son test değerleri karşılaştırıldığında istatistiksel olarak anlamlı farklılıklar bulunmuştur $(p<0,05)$. Erkekler için flamingo denge testi, otur ve eriş testi, durarak çift ayak öne sıçrama, dikey sıçrama ve anaerobik güç, kavrama kuvveti testi, mekik testi, bükülü kol tutunma testi,10mx5 mekik koşusu testleri ön-test ve son-test değerleri karşılaştırıldığında istatistiksel olarak anlamlı farklılıklar bulunmuştur $(\mathrm{p}<0,05)$. Cinsiyete göre karşılaştırma yapıldığında durarak çift ayak öne sıçrama, dikey siçrama ve anaerobik güç, mekik testi, bükülü kol tutunma testi, $10 \mathrm{mx} 5$ mekik koşusu testlerinde istatistiksel 


\title{
8 Haftalık Kuvvet Antrenmanının 13-16 Yaş Arası Çocuklarda Bazı Fiziksel \\ Uygunluk Parametrelerine Etkisinin İncelenmesi
}

olarak anlamlı artışlar görülmüştür $(\mathrm{p}<0,05)$. Flamingo denge testi, otur ve eriş testi ve kavrama kuvveti testleri değerlerinde istatistiksel olarak anlaml farklılıklar görülmemiştir ( $\mathrm{p}>0,05)$.

Sonuç olarak, bu çalışmada 8 haftalık kuvvet antrenmanının 13-16 yaş arası çocukların bazı fiziksel uygunluk özelliklerinin gelişimine katkı sağladığı ve çocuk yaşlarında kuvveti artırmak için kendi vücut ağırlığıyla yapılan egzersizlerin uygun olduğu görülmüştür.

Anahtar Sözcükler: Çocuk, kuvvet, fiziksel uygunluk.

\section{Examination of Effect of Eight-Week Strength Training On Some Physical Fitness Parameters of 13-16 Years Old Children.}

\author{
Arş. Gör. Murat YILMAZ ${ }^{1}$, Prof. Dr. Hasan AKKUŞ ${ }^{2}$
}

1. Adıyaman Üniversitesi Beden Eğitimi Ve Spor Yüksekokulu, mrtyilmaz@adiyaman.edu.tr.

2. Selçuk Üniversitesi Spor Bilimleri Fakültesi, hakkus@selcuk.edu.tr

\section{SUMMARY}

The aim of this study was to investigate the effect on some physical fitness parameters for 8 weeks of strength training for children between 13-16 years.

Research ranging from ages 13-16, 12 male and 10 female students participated in a total of 22 children. In tests and measurements, all children were volunteer and had no problem in terms of health. Mean age, height and body mass of students who participated in the study were for girls $14,50 \pm 1,26$ years, 1,52 $\pm 0,05 \mathrm{~m}$ and $51,00 \pm 8,00 \mathrm{~kg}$, and for boys $14,50 \pm 0,90$ years, $1,62 \pm 0,09 \mathrm{~m}$ and $53,58 \pm 7,10 \mathrm{~kg}$, respectively. Students were performed during eight-week of strength training. Flamingo balance test, sit down and access the test, standing double foot forward jump, vertical jump, anaerobic power, grip strength test, shuttle test, bent arm holding test, $10 \mathrm{mx} 5$ shuttle run were applied to determine on some of physical fitness parameters. Body mass index is calculated by dividing the square of height (m) to body weight $(\mathrm{kg})$,

All of the tests applied in the study according to age group and gender distribution was evaluated by calculating the percentage. For fameles; flamingo balance test, sit down and access the test, the lead pair of feet standing jump, vertical jump and anaerobic power, grip strength test, shuttle test, bent arm holding test, $10 \mathrm{mx} 5$ shuttle run tests compared to pre-test and post-test values statistically significant differences were found $(\mathrm{p}<0,05)$ for boys; flamingo balance test, sit down

\section{ULUSLARARASI BEDEN EĞİTIMİ SPOR REKREASYON VE DANS Dergisi Y11:1, Sayı:1, Aralık 2018, s.47-62}




\section{Haftalık Kuvvet Antrenmanının 13-16 Yaş Arası Çocuklarda Bazı Fiziksel \\ Uygunluk Parametrelerine Etkisinin İncelenmesi}

and access the test, the lead pair of feet standing jump, vertical jump and anaerobic power, grip strength test, shuttle test, bent arm holding test, 10mx5 shuttle run tests compared to pre-test and post-test values statistically significant differences were found $(\mathrm{p}<0,05)$. By comparison by gender standing double foot forward jump, vertical jump and anaerobic power, shuttle test, bent arm holding test, shuttle run $10 \mathrm{mx} 5$ statistically significant increases were observed in tests $(\mathrm{p}<0,05)$ Statistically significant differences were not observed in flamingo balance test, sit down and access the test and grip strength test scores $(\mathrm{p}>0,05)$.

In conclusion, this study of children aged 13-16, 8weeks of strength training contribute to the development of some physical fitness and at these ages, exercises with their own body weight has been shown to be more suitable to increase the strength.

Keywords: Children; strength; physical fitness.

\section{GíRiş}

Spor alışkanlığının temeli çocukluk çağında atılır. Spor gelişmekte olan çocuklar için yalnız organik sağlık ve gelişme için değil, iyi bir şahsiyetin gelişimi, mental sağlığı için gereklidir. Bugün genellikle sporun çocukların her yönden gelişiminde büyük bir rol oynadığına inanılmaktadır. Büyüme çağındaki çocuklarda iskelete ve kaslara bir yük bindiren hareketler, kemiğin büyüklüğünü ve yoğunluğunu arttırır. Çocukluklarını inaktif geçiren bireyler yaşlılıklarında kemik kırılmalarına zemin hazırlamış olur. Yetişkinlikte görülen şişmanlığın temeli genellikle çocuklukta atılır. Şu halde çocukluk çağında başlanılan ve düzenli bir şekilde devam ettirilen egzersizlerin yalnız çocukluk döneminde değil ileri yaşlarda da çeşitli faydaları vardır.

Fiziksel sağlık, gelişim, kişilik oluşumu ve ruh sağlığı açısından spor büyüme çağındaki çocuklar için oldukça önemlidir. Günümüzde sporun çocukların fiziksel ve ruhsal gelişimi açısından gerekli olan, kaliteli bir yaşam ve faydalı sosyal etkinliklerden biri olarak görülen, çocuklarında katılması gerektiği çoğu insan tarafindan kabul edilen bir olgudur (Mengütay 1999). 


\section{Haftalık Kuvvet Antrenmanının 13-16 Yaş Arası Çocuklarda Bazı Fiziksel Uygunluk Parametrelerine Etkisinin İncelenmesi}

Çocuklarda kasların, kemiklerin, organların ve sinir sisteminin gelişim düzeyi ise birbirine göre farkl1lık göstermekte ve bu gelişme fizyolojik ve performans kapasitesini de büyük bir oranda etkilemektedir. Bu değişim ve gelişme sürecinde sportif aktiviteler kassal yapıyı da etkilemektedir. Bu etki, kas yapısındaki kitlesel artışın sağlanması ve kasların uyum göstermesiyle meydana gelmektedir. Düzenli olarak uygulanan sportif aktiviteler kas kompozisyonuna, kas kitlesi oranına olumlu yönde etki etmektedir (Bompa 2000).

Antrenman biliminde, motor performansın önemli bileşenlerinden biri olan kuvvetin ve gelişiminin çocuklar üzerindeki etkisinin incelenmesi önem taşımaktadır (Y1ldiz 2009).

Kuvvet; yaş, boy, kilo ve bütün vücudun kas kütlesindeki artışa bağlı olarak artmaktadır (Muratlı 2007). Sportif verim de kuvvet özelliğindeki artışa bağlı olarak gelişmektedir. Spor bilimciler çocuk ve gençlerde kuvvet çalışmalarını uygulamanın sportif başarıyı arttırmak için gerekli olduğunu savunmaktadır (Muratlı 1997). Çocuklarda kas kuvvetinin artışı yaşa, cinsiyete, olgunlaşma düzeyine, önceki fiziksel etkinlik düzeyine ve beden ölçülerine bağlı olarak değişiklik göstermektedir (Özer 1998).

Kuvvet antrenmanı kas kitlesinin büyümesine neden olarak kuvvette artış meydana getirir. Kas kuvveti dayanıklılığ geliştirilir. Kasın çabukluk özelliğinde gelişme sağlar (Dündar 2007).

Ulusal Kuvvet ve Kondisyon Birliği (NSCA), çocuklara yönelik kuvvet antrenmanının doğru bir yöntemle uygulandığında güvenliği olabileceği, kuvvetlerinde, motor becerilerinde, spor performanslarında artışa yardımcı olacağını ve sakatlıklardan korunmayı sağlayacağını belirtmektedir (Faigenbaum ve ark 2009). 
8 Haftalık Kuvvet Antrenmanının 13-16 Yaş Arası Çocuklarda Bazı Fiziksel

Uygunluk Parametrelerine Etkisinin İncelenmesi

Kuvvet çalışmaları, kişinin kuvvet dayanıklılığı ya da kuvveti kullanma yeteneğini artırmak için uygulanan direnç metodudur. Kuvvet çalışmaları, serbest ağırlıklar, vücut ağırlığı, kondisyon makineleri ya da diğer aletlerle (elastik bantlar, cimnastik topu) uygulanabilir; kuvvet antrenmanları aynı zamanda dayanıklılığın artmasını da sağlar (Holly ve ark 2003).

$\mathrm{Bu}$ çalışmanın amacı 8 haftalık kuvvet antrenmanının 13-16 yaş arası çocukların bazı fiziksel uygunluk parametreleri üzerine etkisini incelemektir. 
8 Haftalık Kuvvet Antrenmanının 13-16 Yaş Arası Çocuklarda Bazı Fiziksel

Uygunluk Parametrelerine Etkisinin İncelenmesi

\section{YÖNTEM}

Araştırmaya yaşları 13-16 arasında değişen, egzersiz yapmasına sağlık açısından engeli bulunmayan, 12 erkek ve 10 kadın öğrenci toplam 22 çocuk katılmıştır. Çalışma öncesinde deneklerin doktor kontrolünden geçirilmesi sağlanarak, egzersiz testlerine katılmalarında sakınca olmadığına dair doktor raporu alınmıştır. Deneklere çalışmanın amacı ve uygulama süreçleri sözlü olarak ayrıntılı açıklanıp, ayrıca deneklerden çalışmayla ilgili yazılı gönüllü katılım onam formunu doldurmaları istenmiştir.

Sekiz haftalık kuvvet antrenmanı programı (3 gün/hafta).

\begin{tabular}{llll}
\hline Egzersiz & Set Sayısı & Tekrar Sayısı & $\begin{array}{l}\text { Dinlenme süresi } \\
\text { (sn) }\end{array}$ \\
\hline Birdirbir Oyunu & 3 & 5 & $15-20$ \\
\hline Kanguru Sıçraması & 4 & 5 & $30-40$ \\
\hline $\begin{array}{l}\text { 3 Adım Sağ 3 Adım Sol } \\
\text { Kanguru Sıçraması }\end{array}$ & 4 & 3 & $30-40$ \\
\hline Horoz Dövüşü & 3 & 1 & $15-20$ \\
\hline Halat Çekme Yarışı & 3 & 1 & $30-40$ \\
\hline Halata Tırmanma & 3 & 1 & $30-40$ \\
\hline El Arabası & 4 & $10-15$ & $30-40$ \\
\hline Pliometrik Sıçrama & 4 & 6 & $40-60$ \\
\hline $\begin{array}{l}\text { Şınav } \\
\text { Mekik }\end{array}$ & 3 & 10 & $30-40$ \\
\hline $\begin{array}{l}\text { Aynı Kilodaki Eşlerle } \\
\text { Adam Taşımaca Oyunu }\end{array}$ & 3 & 10 & $30-40$ \\
\hline Lunges & 3 & 5 & $30-40$ \\
\hline $\begin{array}{l}\text { Aynı Kilodaki Eşlerle } \\
\text { Adam İtme Oyunu }\end{array}$ & 4 & & $30-40$ \\
\hline
\end{tabular}

\section{Araştırmada Uygulanan Ölçüm ve Testler}

- Flamingo Denge Testi

- Otur ve Eriş Testi

- Durarak Çift Ayak Öne Siçrama

- Dikey Siçrama ve Anaerobik Güç Testi

- Kavrama Kuvveti Testi

- Mekik Testi

- Bükülü Kol Tutunma Testi

- Mekik Koşusu Testi (10mx5)

- Vücut Kompozisyonunun Belirlenmesi

ULUSLARARASI BEDEN EĞITIMII SPOR REKREASYON VE DANS Dergisi Y11:1, Sayı:1, Aralık 2018, s.47-62 
8 Haftalık Kuvvet Antrenmanının 13-16 Yaş Arası Çocuklarda Bazı Fiziksel

Uygunluk Parametrelerine Etkisinin İncelenmesi

\section{BULGULAR}

$\mathrm{Bu}$ bölümde araştırmanın konusu ve yöntemi çerçevesinde elde edilen bulgular tablolar halinde sunulmuştur.

Tablo 1. Araştırmaya katılan kadın ve erkek çocukların fiziksel özelliklerinin karşılaştırılması.

\begin{tabular}{llll}
\hline & $\operatorname{Kadın}(\mathbf{n}=10)$ & $\operatorname{Erkek}(\mathbf{n}=12)$ & t-testi \\
\hline Yaş (yıl) & $14,50 \pm 1,26$ & $14,50 \pm 0,90$ & 00,0 \\
Boy Uzunluğu (m) & $1,52 \pm 0,05$ & $1,62 \pm 0,09$ & $2,79 *$ \\
Vücut Ağırlığı $(\mathbf{k g})$ & $51,00 \pm 8,00$ & $53,58 \pm 7,10$ & 0,80 \\
Vücut Kütle İ́ndeksi $\left(\mathbf{k g} / \mathbf{m}^{\mathbf{2}}\right)$ & $21,86, \pm 2,97$ & $20,32 \pm 1,05$ & 1,67 \\
\hline *p $<0,05$ & &
\end{tabular}

*p $<0,05$

Tablo 1 deki verilere göre çalışmaya katılan kadın ve erkek çocukların fiziksel özellikleri karşılaştırıldığında erkeklerin boy uzunluğunun kadınlardan anlamlı düzeyde yüksek olduğu görülmüştür $(p<0,05)$. Cinsiyetler arasında yaş, vücut ağırlığı ve vücut kütle indeksi değerleri açısından bir fark gözlenmediği ortaya çıkmıştır.

Tablo 2. Sekiz haftalık kuvvet antrenmanlarının 13-16 yaş erkek çocuklarda bazı fiziksel uygunluk değişkenleri üzerine etkisi (Ortalama \pm Ssapma).

\begin{tabular}{llll}
\hline & \multicolumn{3}{c}{ KADIN } \\
\hline & Ön-test & Son-test & t-dĕgeri \\
\hline FDT (sayi) & $3,70 \pm 0,90$ & $2,60 \pm 1,07$ & $3,97^{*}$ \\
OET (cm) & $15,10 \pm 5,75$ & $18,70 \pm 5.16$ & $5,21^{*}$ \\
DÇAÖS (cm) & $179,80 \pm 13,63$ & $187,70 \pm 16,57$ & $6,02^{*}$ \\
DST (cm) & $33,70 \pm 5,83$ & $37,20 \pm 5,86$ & $7,72^{*}$ \\
AGT (watt) & $378,32 \pm 106,90$ & $416,86 \pm 110,85$ & $7,25^{*}$ \\
KKT $_{\text {sağ el }(\mathbf{k g})}$ & $34,39 \pm 7,49$ & $35,50 \pm 7,80$ & $3,30^{*}$ \\
KKT $_{\text {sol el }(\mathbf{~ k g ) ~}}$ & $32,00 \pm 7,94$ & $33,50 \pm 8,28$ & $4,02^{*}$ \\
MT (adet) $_{\text {BKT (sn) }}$ & $21,10 \pm 2,23$ & $27,70 \pm 3,59$ & $7,07^{*}$ \\
MKT (sn) & $14,51 \pm 4,22$ & $21,66 \pm 7,06$ & $6,00^{*}$ \\
\hline
\end{tabular}


FDT=Flamingo denge testi, OET=Otur ve eriş testi, DÇAÖS=Durarak çift ayak öne sıçrama testi, DST=Dikey sıçrama testi, AGT=Anaerobik güç testi, KKTsağ el=Kavrama kuvveti testi sağ el, KKTsol el=Kavrama kuvveti testi sol el, MT=Mekik testi, BKTT=Bükülü kol tutunma testi, MKT=Mekik koşusu testi.

$* \mathrm{p}<0,05$

Tablo 2. Verilere göre incelendiğinde kadınların antrenman öncesi ve antrenman sonrası FDT, OET, KKTsağ el, KKTsol el, DÇAÖS, DST, AGT, MT, BKTT, MKT, değerleri karşılaştırıldığında istatistiksel olarak anlamlı artışlar olduğu görülmüştür $(\mathrm{p}<0,05)$.

\section{Tablo 3. Sekiz haftalık kuvvet antrenmanlarının 13-16 yaş erkek çocuklarda bazı fiziksel uygunluk değişkenleri üzerine etkisi (Ortalama \pm Ssapma).}

\begin{tabular}{|c|c|c|c|}
\hline \multicolumn{4}{|c|}{ ERKEK } \\
\hline & Ön-test & Son-test & t-değeri \\
\hline FDT (sayı) & $4,66 \pm 1,49$ & $2,91 \pm 1,44$ & $8,04^{*}$ \\
\hline OET $(\mathrm{cm})$ & $11,08 \pm 4,27$ & $14,58 \pm 5,63$ & $6,79 *$ \\
\hline DÇAÖS (cm) & $202,25 \pm 25,35$ & $211,66 \pm 24,90$ & $7,48 *$ \\
\hline DST (cm) & $41,41 \pm 8,00$ & $45,75 \pm 0,12$ & $7,13 *$ \\
\hline AGT (watt) & $489,01 \pm 147,63$ & $540,11 \pm 155,66$ & $6,48^{*}$ \\
\hline 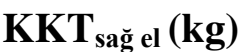 & $39,91 \pm 7,63$ & $42,66 \pm 7,72$ & $6,41 *$ \\
\hline $\mathbf{K K T}_{\text {sol el }}(\mathbf{k g})$ & $39,00 \pm 7,12$ & $41,33 \pm 7,83$ & $4,20 *$ \\
\hline MT (adet) & $21,83 \pm 2,94$ & $31,08 \pm 3,17$ & $9,85^{*}$ \\
\hline BKTT (sn) & $26,78 \pm 12,74$ & $41,85 \pm 15,59$ & $8,67 *$ \\
\hline MKT (sn) & $23,32 \pm 0,69$ & $22,14 \pm 0,48$ & $7,65^{*}$ \\
\hline
\end{tabular}

FDT=Flamingo denge testi, OET=Otur ve eriş testi, DÇAÖS=Durarak çift ayak öne sıçrama testi, DST=Dikey sıçrama testi, AGT=Anaerobik güç testi, KKTsağ el=Kavrama kuvveti testi sağ el, KKTsol el=Kavrama kuvveti testi sol el, MT=Mekik testi, BKTT=Bükülü kol tutunma testi, MKT=Mekik koşusu testi. $* \mathrm{p}<0,05$

Tablo 3. deki verilere göre erkeklerin antrenman öncesi ve sonrası FDT, OET, KKTsă̆ el, KKTsol el, DÇAÖS, DST, AGT, MT, BKTT, MKT değerleri karşılaştırıldığında istatistiksel olarak anlamlı artışlar ortaya çıkmıştır $(\mathrm{p}<0,05)$. 
Tablo 4. Kuvvet antrenman öncesi bazı fiziksel uygunluk değişkenlerinin cinsiyete göre karşılaştırılması (Ortalama \pm Ssapma).

\begin{tabular}{llll}
\hline & Kadınlar & Erkekler & t-değeri \\
\hline FDT (sayı) & $3,70 \pm 0,94$ & $4,66 \pm 1,49$ & 1,76 \\
OET (cm) & $15,10 \pm 5,75$ & $11,08 \pm 4,27$ & 1,92 \\
DÇAÖS (cm) & $179,80 \pm 13,63$ & $202,25 \pm 25,35$ & $2,50^{*}$ \\
DST (cm) & $33,70 \pm 5,83$ & $41,41 \pm 8,00$ & $2,53^{*}$ \\
AGT (watt) & $378,32 \pm 106,90$ & $489,01 \pm 147,63$ & 1,97 \\
KKT $_{\text {sağ el }(\mathbf{k g})}$ & $34,39 \pm 7,49$ & $39,91 \pm 7,63$ & 1,82 \\
KKT $_{\text {sol el }(\mathbf{k g})}$ & $32,00 \pm 7,94$ & $39,00 \pm 7,12$ & 2,17 \\
MT (adet) & $21,10 \pm 2,23$ & $21,83 \pm 2,94$ & 0,64 \\
BKTT (sn) & $14,51 \pm 4,22$ & $26,78 \pm 12,74$ & $2,90^{*}$ \\
MKT (sn) & $25,60 \pm 1,51$ & $23,32 \pm 0,69$ & $4,68^{*}$ \\
\hline
\end{tabular}

FDT=Flamingo denge testi, OET=Otur ve eriş testi, DÇAÖS=Durarak çift ayak öne sıçrama testi, DST=Dikey sıçrama testi, AGT=Anaerobik güç testi, KKTsă̆ el=Kavrama kuvveti testi sağ el, KKTsol el=Kavrama kuvveti testi sol el, MT=Mekik testi, BKTT=Bükülü kol tutunma testi, MKT=Mekik koşusu testi.

$* \mathrm{p}<0,05$

Tablo 4'e bakıldığında, kadınlar ve erkeklerin antrenman öncesi DÇAÖS, DST, BKTT, MKT değerlerinde anlamlı farkl1lıklar olduğu görülmüştür $(\mathrm{p}<0,05)$. FDT, OET, AGT, KKTsă̆ el, KKTsol el, MT değerleri arasında anlamlı farklılıklar olduğu görülmemiştir ( $p>0,05)$.

Tablo 5. Kuvvet antrenmanı sonrası bazı fiziksel uygunluk değişkenlerinin cinsiyete göre karşılaştırılması (Ortalama \pm Ssapma).

\begin{tabular}{llll}
\hline & Kadınlar & Erkekler & t-değeri \\
\hline FDT (sayı) & $2,60 \pm 1,07$ & $2,91 \pm 1,44$ & 0,57 \\
OET (cm) & $18,70 \pm 5,16$ & $14,58 \pm 5,63$ & 1,77 \\
DÇAÖS (cm) & $187,70 \pm 16,57$ & $211,66 \pm 24,90$ & $2,59^{*}$ \\
DST (cm) & $37,20 \pm 5,86$ & $45,75 \pm 0,12$ & $2,77^{*}$ \\
AGT (watt) & $416,86 \pm 110,85$ & $540,11 \pm 155,66$ & 2,09 \\
KKT sağ el (kg) $_{\text {KKT }}$ sol el (kg) & $35,50 \pm 7,80$ & $42,66 \pm 7,72$ & 2,15 \\
MT (sayı) & $33,50 \pm 8,28$ & $41,33 \pm 7,83$ & 2,27 \\
BKTT (sn) & $27,70 \pm 3,59$ & $31,08 \pm 3,17$ & $2,34^{*}$ \\
MKT (sn) & $21,66 \pm 7,06$ & $41,85 \pm 15,59$ & $3,77^{*}$ \\
\hline
\end{tabular}

FDT=Flamingo denge testi, OET=Otur ve eriş testi, DÇAÖS=Durarak çift ayak öne sıçrama testi, DST=Dikey sıçrama testi, AGT=Anaerobik güç testi, KKTsă̆ el=Kavrama kuvveti testi sağ el, KKTsol el=Kavrama kuvveti testi sol el, MT=Mekik testi, BKTT=Bükülü kol tutunma testi, MKT=Mekik koşusu testi. $* \mathrm{p}<0,05$ 


\section{Haftalık Kuvvet Antrenmanının 13-16 Yaş Arası Çocuklarda Bazı Fiziksel Uygunluk Parametrelerine Etkisinin İncelenmesi}

Tablo 5 verilerine göre kuvvet antrenmanı sonrası cinsiyetler arası sonuçlar incelendiğinde kadınlar ve erkeklerin antrenman sonrası DÇAÖS, DST, MT, BKTT, MKT, değerlerinde anlamlı bir artış görülmüştür $(p<0,05)$. FDT, OET, AGT, KKTsağ el, KKTsol el değerlerinde istatistiksel olarak anlamlı farklılıklar görülmemiştir ( $\mathrm{p}>0,05)$.

\section{TARTIŞMA VE SONUÇ}

Bu çalışmada 8 haftalık kuvvet antrenmanının 13-16 yaş arası çocukların bazı fiziksel uygunluk parametreleri üzerine etkisini incelemek amaçlanmıştı. Bu amaç doğrultusunda, araştırma fiziksel parametreleri birbirine benzer olan erkek ve kadın öğrenciler üzerinde gerçekleştirilmiş ve bazı fiziksel uygunluk parametreler ölçülmüş̧ür.

Her yaş grubunda ve cinsiyetler arasında gelişim gösterdiği tespit edilen durarak uzun atlama, patlayıcı kuvvet göstergelerinden birisi olarak kabul edilmektedir (Zorba 2001).

Yapmış olduğumuz çalışmada kadın ve erkek çocukların patlayıcı kuvvetleri

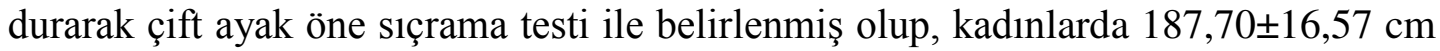
ve erkeklerde $211,66 \pm 24,90 \mathrm{~cm}$ 'dir. İstatistiksel olarak anlamlı artışlar görülmüştür. Çift ayak durarak uzun atlama testi sonucunda erkek çocukların değerleri kızlarınkinden daha iyi çıkmıştır.

Pense ve Harbili (2001), Kızılet ve ark (2010), Atılgan (2010), Kızılakşam (2006), Er (1995), Çalış (1992), Şenel (1995), Demir (2001), Koç (1996) ve Çelebi (2000) bizim çalışmamıza benzer çalışmalar yapmışlardır. Araştırma bulguları kadınlar; Kızılet ve ark, Er, Şenel, Demir, Çelebi'nin çalışmalarından yüksek, Koç ve

\section{ULUSLARARASI BEDEN EĞİTIMİ SPOR REKREASYON VE DANS Dergisi} Y11:1, Sayı:1, Aralık 2018, s.47-62 


\section{Haftalık Kuvvet Antrenmanının 13-16 Yaş Arası Çocuklarda Bazı Fiziksel Uygunluk Parametrelerine Etkisinin İncelenmesi}

Çalış’ın çalışmalarından düşüktür. Erkekler; Kızılet ve ark, Kızılakşam, Er, Çalış, Şenel, Çelebi, Demir, Koç’un çalışmalarından yüksektir.

Bu çalışmada kavrama kuvveti testi sonucu kadınlar sağ el ve sol el pençe kuvveti sırasıyla $35,50 \pm 7,80 \mathrm{~kg}$ ve $33,50 \pm 8,28 \mathrm{~kg}$, erkekler sağ el ve sol el pençe kuvveti sırasıyla $42,66 \pm 7,72 \mathrm{~kg}$ ve $41,33 \pm 7,83 \mathrm{~kg}$ bulunmuştur.

Uzuncan (1991), Yazarer ve ark (2004), Zorba ve ark (1995), İşleğen (1989) bizim çalışmamıza benzer çalışmalar yapmışlardır. Araştırma bulguları; Uzuncan, Yazarer ve ark, Zorba ve ark'nın ve İşleğen'in bulgularından yüksektir. Bunun sebebi olarak uygulanan antrenman metodunun, büyüme dönemlerinin, spor yaşının, spor branşının ve antrenman periyodunun farklı olması gösterilebilir. Çocuklarda kas kuvvetinin gelişimi yaş, vücut yapısı ve cinsel olgunlaşmayla ilgilidir (Seger ve Thorstensson 2000).

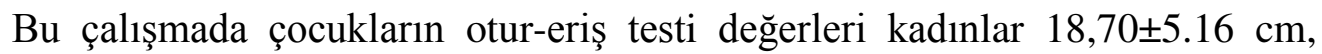
erkekler 14,58 $\pm 5,63 \mathrm{~cm}$ bulunmuştur. Kadınların erkeklerden daha esnek olduğu görülmüştür.

Pense ve Harbili (2001), Faigenbaum ve ark (1996), Çalış (1992), Uzuncan (1991), Zorba ve ark (1995), Şenel (1995), İşleğen ve ark (1989) bizim çalışmamıza benzer çalışmalar yapmışlardır. Araştırma bulguları; kadınların değerleri, Çalış ve İşleğen ve ark'larının değerlerinden yüksek, Uzuncan, Zorba ve ark ve Şenel'in çalışmalarından düşüktür. Erkeklerin değerleri, Çalış ve İşleğen ve ark'larının değerlerinden yüksek, Uzuncan, Zorba ve ark ve Şenel'in çalışmalarından düşüktür.

Kuvvet antrenmanlarının anaerobik gücü artırdığg bilinmekle birlikte bu çalışma sonucunda çocukların anaerobik gücünü değerlendiren dikey sıçrama test

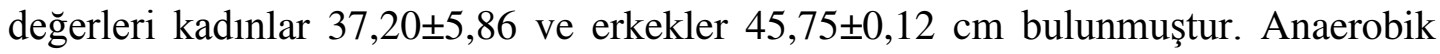

\section{ULUSLARARASI BEDEN EĞİTIMİ SPOR REKREASYON VE DANS Dergisi Y11:1, Sayı:1, Aralık 2018, s.47-62}




\section{Haftalık Kuvvet Antrenmanının 13-16 Yaş Arası Çocuklarda Bazı Fiziksel Uygunluk Parametrelerine Etkisinin İncelenmesi}

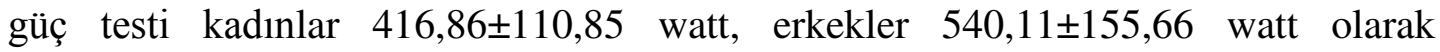
bulunmuştur.

Koçak ve ark (2003), Gül ve ark (2006), Akpınar ve ark (2003), Behm ve ark (2008), Yazarer ve ark (2004), Ataberk ve ark (2010), Eskikaya (2011), (Robert ve ark 2010), (Ziyagil ve ark 2010) bizim çalışmamıza benzer çalışmalar yapmışlardır. Yaptıkları çalışmalarda kuvvet antrenmanı sonucunda dikey sıçrama testinde istatistiki değerlere göre anlamlı artış gözlemlemişlerdir.

Yapmış olduğumuz çalışmada kadın ve erkek çocukların flamingo denge testi

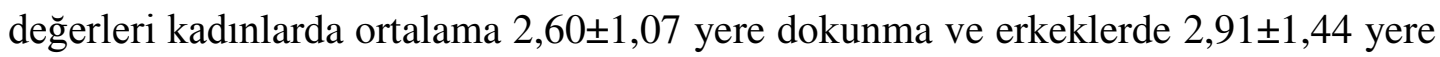
dokunma olarak bulunmuştur.

Flamingo denge testi sonuçları kadın çocukların değerleri erkek çocukların değerinden daha iyi çıkmıştır. Yaptığımız çalışmaya benzer diğer çalışmalar Kızılakşam (2006), Er (1995), Demir (2001), Çelebi (2000), Koç (1996) Araştırma bulguları; Kızılakşam, Er, Demir, Çelebi ve Koç’un çalışmalarından yüksek çıkmıştır.

Yapmış olduğumuz çalışmada gövde kuvvetini belirlemek için mekik testi


olarak bulunmuştur.

Pekel ve ark (2006), Kürkçü ve ark (2001), Yılmaz ve ark (2003), Er (1995), Çalış (1992), Zorba ve ark (1995), Kızılakşam (2006), Çelebi (2000), Demir (2001), Koç (1996) bizim çalışmamıza benzer çalışmalar yapmışlardır. Araştırma bulguları; Pekel ve ark değerlerinden düşük, Kürkçü ve ark, Kızılakşam, Er, Çalış, Şenel, Çelebi, Demir, Koç'un çalışmalarından yüksektir. 


\section{Haftalık Kuvvet Antrenmanının 13-16 Yaş Arası Çocuklarda Bazı Fiziksel Uygunluk Parametrelerine Etkisinin İncelenmesi}

$\mathrm{Bu}$ çalışmada kas dayanıklılığını belirlemek için bükülü kol tutunma testi uygulanmıştır. Bükülü kol tutunma testi kadınlarda 21,66 $\pm 7,06$ sn ve erkeklerde $41,85 \pm 15,59$ sn olarak bulunmuştur.

Yılmaz ve ark (2003), Kızılakşam (2006), Çelebi (2000) bizim çalışmamıza benzer çalışmalar yapmışlardır. Araştırma bulguları; Yılmaz ve ark paralellik göstermekte, Kızılakşam ve Çelebi’nin değerlerinden yüksektir.

$\mathrm{Bu}$ çalışmada sürat ve çevikliği belirlemek için mekik koşusu (10mx5) testi

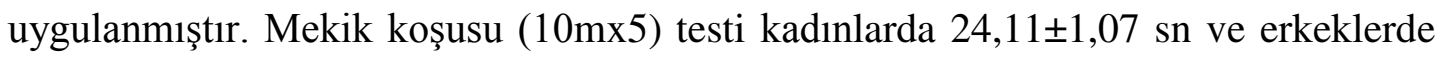
$22,14 \pm 0,48$ sn olarak bulunmuştur.

Kızılakşam (2006), Er (1995), Çalış (1992) Çelebi (2000), Demir (2001), Koç (1996) bizim çalışmamıza benzer çalışmalar yapmışlardır. Araştırma bulguları; kadınların değerleri, Koç’un çalışmasından düşük, Kızılakşam, Er, Çalış, Çelebi, Demir'in çalışmalarından yüksek çıkmıştır. Erkeklerin değerleri, Er ve Koç'un çalışmasından düşük, Kızılakşam, Çalış, Çelebi ve Demir'in çalışmalarından yükssek çıkmıştır.

Araştırmamıza denek olarak katılan 12 erkek ve 10 kadın öğrencinin vücut kompozisyonu incelendiğinde kadınlar $21,86, \pm 2,97 \mathrm{~kg} / \mathrm{m}^{2}$ ve erkekler $20,32 \pm 1,05$ $\mathrm{kg} / \mathrm{m}^{2}$ olarak bulunmuştur. Denekler Dünya Sağlık Örgütünün (WHO) VKİ Sınıflamasına göre normal kilolu $\left(18,5-24,99 \mathrm{~kg} / \mathrm{m}^{2}\right)$ olarak kabul edilmiştir.

Kızılakşam (2006), Koç (1996), Demir (2001), Çelebi (2000) bizim çalışmamıza benzer çalışmalar yapmışlardır. Araştırma bulguları; Kızılakşam, Koç, Demir ve çelebinin çalışmalarından yüksek çıkmıştır. Genel olarak baktığımız zaman farklılıkların görülmesinin sebebi: Uygulanan antrenman metodlarının, büyüme dönemlerinin, spor yaşının, spor branşının ve antrenman periyodlarının farklı olmasından kaynaklandığını söyleyebiliriz.

\section{ULUSLARARASI BEDEN EĞİTIMİ SPOR REKREASYON VE DANS Dergisi Y11:1, Sayı:1, Aralık 2018, s.47-62}




\section{Haftalık Kuvvet Antrenmanının 13-16 Yaş Arası Çocuklarda Bazı Fiziksel Uygunluk Parametrelerine Etkisinin İncelenmesi}

Sonuç olarak 8 haftalık kuvvet antrenmanı yapan çocukların vücut kompozisyonu, esneklik, kas kuvveti ve kardiyovasküler dayanıklılığı geliştirdiği söylenebilir. Spor bilimcileri, yöneticiler ve basından da destek alınarak insan sağlı̆̆ açısından sporun önemi vurgulanmalıdır. "Kısaca spor bir yaşam biçimi olmalıdır".

\section{Kaynakça}

Akpınar P, Nalçakan GR, Akhisaroğlu M, Kutay E, Koşay C, Bediz ŞC. Ritmik Jimnastikçilerde Sıçrama Yükseklikleri, İzokinetik Kuvvet ve EMG Profillerinin Karşıllaştırılması. Ankara, Spor Bilimleri Dergisi, Hacettepe Journal of SportSciencesi, 2003; 3: 104-113.

Ataberk ÇH, Çolak R, Açıkada C. Antrenmanın Sıçrama Performansı Üzerine Etkisinin Farklı Yaş Grubu Çocuklarda incelenmesi, Niğde Üniversitesi Beden Eğitimi ve Spor Bilimleri 2010; 4: 24-29.

Atılgan O. 12-14 Yaş Grubu Basketbol Oyuncularının Çabukluk Ve Sıçrama Yetilerine Farklı Kuvvet Antrenmanlarının Etkisi. İstanbul, Marmara Üniversitesi Sağlı Bilimleri Enstitüsü Beden Eğitimi ve Spor Anabilim Dalı, Yüksek Lisans Tezi, 2010.

Behm DG, Faigenbaum AD, Falk B ve Klentrou P. Canadian Society for Exercise Physiology Position Paper: Resistance Training in Children and Adolescents. Appl. Physiol. Nutr. Metab. 2008; 33: 547-561.

BompaT. Total Training for Young Champions, HumanKinetics, 2000; 1: 21, 93-149.

Çalış M. Beden Eğitimi Dersine Katılan Katılmayan ve Spor Yapan 15-16 Yas Grubu Erkek Öğrencilerin Fizyolojik Parametrelerinin Eurofit Test Bataryasıyla Mukayesesi. Ankara, Yayımlanmamış, Gazi Üniversitesi. Sağlık Bilimleri Enstitüsü, Yüksek Lisans Tezi, 1992.

Çelebi F. 12-14 Yaş Grubu Puberte Dönemi Spor Yapan ve Sedanter Öğrencilerin Posturel ve Biyomotor Özelliklerinin Karşılaştırılması. Muğla, Muğla Üniversitesi Sosyal Bilimler Enstitüsü, Yüksek Lisans Tezi, 2000.

Demir İ. Beden Eğitimi ve Sporun Beceri, Yetenek Gelişimlerine Etkisi 11-13 Yaş Grubunda Eurofit Test Değerlendirmesi. Sakarya, Sakarya Üniversitesi, Sosyal Bilimler Enstitüsü, Beden Eğitimi ve Spor Öğretmenliği Anabilim Dalı, Yüksek Lisans Tezi, 2001.

Dündar U. Antrenman Teorisi. 7. Baskı, Bağırgan Yayınevi. Ankara. 2007; s:133-146.

Er D. Eurofit Testleri İle 12-14 Yaş Grubu Öğrencilerin Fiziksel Uygunluk Normlarının Araştırılması Kastamonu Uygulaması. Ankara, Gazi Üniversitesi Sağlık Bilimleri Enstitüsü, Beden Eğitimi ve Spor Öğretmenliği Anabilim Dalı, Yüksek Lisans Tezi, 1995.

Eskikaya P. 14-16 Yaş Erkek Basketbolcularda Tek Eklemli Kuvvet Çalışmaları İle Çok Eklemli Fonksiyonel Kuvvet Çalışmalarının Performansa Etkilerinin Karşılaştırılması. İstanbul, Marmara Üniversitesi Sağllk Bilimleri Enstitüsü Hareket ve Antrenman Anabilim Dalı, Yüksek Lisans Tezi, 2011.

ULUSLARARASI BEDEN EĞİTIMI SPOR REKREASYON VE DANS Dergisi Y11:1, Sayı:1, Aralık 2018, s.47-62 


\section{Haftalık Kuvvet Antrenmanının 13-16 Yaş Arası Çocuklarda Bazı Fiziksel Uygunluk Parametrelerine Etkisinin İncelenmesi}

Faigenbaum A, Kraemer W.J, Blimkie C.J.R, Jeffreys I, Michell J, Lyle N, Mike Rowland W. T. Youth Resistance Training: Update Position Statement Paperfrom the National Strength and Condition Association, Journal of Strength and Conditioning Research. 2009; 4: 23.

Faigenbaum AD, Westcott WL, Micheli LJ, Outerbridge AR, Long CJ, Loud RL, Zaichkowsky LD. TheEffect of Strenght Training and Detraining on Children. Journal of Strenght and Conditioning Research. 1996; 10(2):109-114.

Gül GK, Seyrek E, Sugurtin M. 10-12 Yaş Temel Atletizm Spor Eğitimi Alan ve Almayan Erkek Çocuklar Arasındaki Bazı Antropometrik ve Motorik Özeliklerin Karşılaştırılması. Ankara, 2006; 69-71.

Holly J, Benjamin MD, Kimbrerly M Glow. Strength Training for Children and Adolescents. The Physician and Sportmedicine. 2003; 31: 9.

İşleğen Ç. 12-14 Yaş ve 15-17 Yaş Futbol Takımlarının Bazı Fonksiyonel Parametrelerinin Kontrol Grubu ile Karşılaştırılması. Ankara, Spor Hekimliği Dergisi, 1989; 1: 9-15.

Kızılakşam E, Edirne İl Merkezi İlköğretim Okullarındaki 12-14 Yaş Grubu Aktif Olarak Spor Yapan Ve Yapmayan Beden Eğitimi Dersine Giren Öğrencilerin Eurofit Test Bataryaları Uygulama Sonuçlarının Karşılaştırılması. Edirne, Trakya Üniversitesi Sağlık Bilimleri Enstitüsü Beden Eğitimi Ve Spor Anabilim Dalı, Yüksek Lisans Programı, 2006.

Kızılet A, Atılan O, Erdemir İ, 12-14 Yaş Grubu Basketbol Oyuncularının Çabukluk Ve Sıçrama Yetilerine Farklı Kuvvet Antrenmanlarının Etkisi. Atatürk Üniversitesi Beden Eğitimi ve Spor Bilimleri Dergisi, 2010; 2: 44-57.

Koç H. 14-16 Yaş Grubu Hentbolcu ve Beden Eğitimi Dersi Alan Öğrencilerin Bazı Fiziksel ve Fizyolojik Parametrelerinin Eurofit Test Bataryasında Değerlendirilmesi. Ankara, Gazi Üniversitesi Sağlık Bilimleri Enstitüsü Beden Eğitimi ve Spor Anabilim Dalı, Yüksek Lisans Tezi, 1996.

Koçak S, Kartal A. İlk Öğretim Öğrencilerinin Bir Öğretim Döneminde Fiziksel Uygunluk Gelişimlerindeki Değişimin İncelenmesi. Ankara, Gazi Beden Eğitimi ve Spor Bilimleri Dergisi, 2003; 1: 53-60.

Kürkçü R, Hazar F, Canikli A, Çalışkan E, 12-14 Yaş Erkek Çocuklarda Egzersizin Fiziksel Ve Fizyolojik Parametrelere Etkisi. Atatürk Üniversitesi Beden Eğitimi ve Spor Bilimleri Dergisi, 2001; 3: 68-73.

Mengütay, S. Okul Öncesi ve İlkokullarda Hareket Gelişimi ve Spor, (Yayın No:1). İstanbul. Türkiye Jimnastik Fedarasyonu Eğitim Komitesi Yayınları, İstanbul, 1997.

Muratlı S. Çocuk ve Spor. 2. Baskı. Nobel Yayımevi, İstanbul, 2007; s.4-43, 95-116, 163-204.

Muratlı, S. Çocuk ve Spor, Bağırgan Yayımevi Ankara, 1997; 135, 138, 139.

Özer D S. Özer K. Çocuklarda Motor Gelisim. 1. Baskı, Kazancı Matbaacılık, İstanbul, 1998; s.10120.

Pekel HA, Bağcı E, Güzel NA, Onay M, Balcı ŞS, Pepe H, Spor Yapan Çocuklarda Performansla İlgili Fiziksel Uygunluk Test Sonuçlarıyla Antropometrik Özellikler Arasındaki İlişkilerin Değerlendirilmesi. Kastamonu Eğitim Dergisi, 2006; 14: 299-308.

ULUSLARARASI BEDEN EĞİTIMI SPOR REKREASYON VE DANS Dergisi Y11:1, Sayı:1, Aralık 2018, s.47-62 


\section{Haftalık Kuvvet Antrenmanının 13-16 Yaş Arası Çocuklarda Bazı Fiziksel Uygunluk Parametrelerine Etkisinin İncelenmesi}

Pense M, Harbili E. 14-16 Yaş Bayan Basketbolcularda Fizik-Kondisyon Antrenmanlarının Eurofit Testlerine Etkileri. III. Uluslararası Akdeniz Spor Bilimleri Kongresi, Poster 137. 2001.

Robert MM, TerasaS, ZofiaI. KrstynaR, KazarzynaK, JaroslawD, Jarostaw F. Sex differences in growth and performance of track and fieldathletes 11-15 years. J. Of Human Kin. 2010; 24 : 79-85.

Seger JY, Thorstensson A. Muscle Strenght and Electromyogram in Boys and Girls Followed Through Puberty. Eur Appl Physiol 2000; 81: 54-61.

Şenel Ö. Aerobik ve Anaerobik Antrenman Programlarının 13-16 Yaş Grubu Erkek Öğrencilerin Bazı Fizyolojik Parametreleri Üzerine Etkileri. Ankara, Ankara Üniversitesi Sağlık Bilimleri Enstitüsü, Yayımlanmamış Doktora Tezi, 1995.

Uzuncan H. Eurofit Testleri ile 10-12 Yaşları Arasındaki Erkek Öğrencilerin Aerobik Güç ve Fiziksel Uygunluklarının Ölçülmesi. Konya, Selçuk Üniversitesi Sağlık Bilimleri Enstitüsü, Yayımlanmamış Yüksek Lisans Tezi, 1991.

Yazarer İ, Taşmektepligil MY, Ağaoğlu YS, Ağaoğlu SA, Albay F, Eker H. Yaz Spor Okullarında Basketbol Çalışmalarına Katılan Grupların İki Aylık Gelişmelerinin Fiziksel Yönden Değerlendirilmesi. Ankara, Spormetre Bed. Eğit.ve Spor Bil dergisi, 2004; 4: 163-170.

Yıldız İ.Farklı Dirençlerle Uygulanan Kuvvet Antrenmanlarının Kız Çocuklarının Fiziksel Ve KasKuvvet Gelişimlerine Olan Etkisinin İncelenmesi. İstanbul, Marmara Üniversitesi, Yüksek Lisans tezi, 2009.

Yılmaz S, Tatar Y, Ateş O, Tiryaki E, Judo Sporunun Görme Engelli Öğrenciler Üzerine Etkisinin Bazı Parametreler Açısından İncelenmesi. İstanbul Üniversitesi Spor Bilimleri Dergisi, 2003; 11: 173-176.

Ziyagil M.A, Türkmen M, Sivrikaya H, Eliöz M, Çebi M. Samsun ilindeki 14-17 yaş erkek ve kız öğrencilerinin fiziksel ve fonksiyonel özelikleri arasındaki ilişki, Spor ve Performans Araştırmaları Dergisi, 2010; 1: 1-19.

Zorba E, Kalkavan A, Ağaoğlu SA, Karakuş S, Çolak H. Farklı Spor Branşlarında Bazı Fiziksel Uygunluk Değerlerinin Sedanter Grupla Karşılaştırılması. Ankara, G.O. Beden Eğitimi ve Spor Bilimleri Dergisi, 1995; 3: 25-35.

Zorba E. Fiziksel Uygunluk, 2. Bask1, Gazi Kitabevi, Ankara, 2001.

ULUSLARARASI BEDEN EĞİTIMI SPOR REKREASYON VE DANS Dergisi Y11:1, Sayı:1, Aralık 2018, s.47-62 